\title{
Article \\ Oral Health-Related Quality-of-Life According to Dental Caries Severity, Body Mass Index and Sociodemographic Indicators in Children with Special Health Care Needs
}

\author{
Rawan Rasheed Alwattban ${ }^{1}$, Lama Saleh Alkhudhayr ${ }^{1}$, Sanaa Najeh Al-Haj Ali ${ }^{2, *(1)}$ and Ra'fat Ibrahim Farah ${ }^{3}$ (D) \\ 1 Dental Intern, College of Dentistry, Qassim University, Qassim 51452, Saudi Arabia; \\ Rawan.alwattban@gmail.com (R.R.A.); Lama.s.alkhudhair@gmail.com (L.S.A.) \\ 2 Department of Orthodontic and Pediatric Dentistry, College of Dentistry, Qassim University, \\ Qassim 51452, Saudi Arabia \\ 3 Department of Prosthetic Dental Sciences, College of Dentistry, Qassim University, \\ Qassim 51452, Saudi Arabia; dr.rafat.farah@qudent.org or ri.farah@qu.edu.sa \\ * Correspondence: s.alhajali@qu.edu.sa or dr.sanaa.alhajali@qudent.org; Tel.: +966-504-603-339; \\ Fax: +966-016-380-1762
}

\section{check for}

updates

Citation: Alwattban, R.R.; Alkhudhayr, L.S.; Al-Haj Ali, S.N.; Farah, R.I. Oral Health-Related Quality-of-Life According to Dental Caries Severity, Body Mass Index and Sociodemographic Indicators in Children with Special Health Care Needs. J. Clin. Med. 2021, 10, 4811. https://doi.org/10.3390/jcm10214811

Academic Editors: Dirk Ziebolz and Gerhard Schmalz

Received: 2 September 2021

Accepted: 18 October 2021

Published: 20 October 2021

Publisher's Note: MDPI stays neutra with regard to jurisdictional claims in published maps and institutional affiliations.

Copyright: (c) 2021 by the authors. Licensee MDPI, Basel, Switzerland. This article is an open access article distributed under the terms and conditions of the Creative Commons Attribution (CC BY) license (https:// creativecommons.org/licenses/by/ $4.0 /)$
Abstract: This study aimed to assess the impact of dental caries' severity, body mass index (BMI) and sociodemographic factors on oral health-related quality of life (OHRQoL) for special health care needs (SHCN) children and the suitability of their caregivers as proxies to determine OHRQoL. This cross-sectional study recruited 107 pairs of SHCN children and their caregivers and asked them to complete a questionnaire on sociodemographic issues as well as the Arabic version of the early childhood oral health impact scale (A-ECOHIS). This was followed by a dental examination. Dental caries was measured using the $\mathrm{dmft} / \mathrm{DMFT}$ index, while caries' severity was also determined. The children's height and weight were measured, and BMI $\left(\mathrm{kg} / \mathrm{m}^{2}\right)$ was recorded. Data were analyzed statistically using $t$-test, one-way ANOVA, and Poisson regression models. Our results revealed that the A-ECOHIS score was 10.93, while the OHRQoL was affected in $95.3 \%$ of children. The most-reported item was 'pain in the teeth, mouth, or jaws' (48.7\%). By regression analysis, caries-free children (Odds Ratio (OR): 0.650) or those who had moderate caries (OR: 0.551) were less likely to have a negative impact on their OHRQoL than those with severe caries. Additionally, those whose caregivers had a maximum primary education (OR: 0.656) or whose occupation was in the health sector (OR: 0.721) were less likely to have a negative impact on their OHRQoL. Those who were $\leq 6$ years old (OR: 1.188) were more likely to have a negative impact. BMI did not have a significant impact on the OHRQoL of the children. Further, we detected a significant positive correlation between children's dmft/DMFT scores and the A-ECOHIS scores reported by the mothers. Given these variables, which included dental caries' severity, but not BMI, and caregivers' education level and occupation, plus the child's age group, we found a significant impact on the OHRQoL. However, we found that mothers were better proxies for their children's OHRQoL.

Keywords: body mass index; children; dental caries; oral health; quality of life; special health care needs

\section{Introduction}

The American Academy of Pediatric Dentistry (AAPD) defines special health care needs (SHCN) as 'any physical, developmental, mental, sensory, behavioral, cognitive, or emotional impairment that requires medical management, health care intervention, and/or use of specialized services, and may impose limitations in performing daily activities or substantial limitations in a major life activity' [1]. Medically compromised children in this category were reported to suffer a greater risk of oral diseases throughout their lives [2], as well as unmet dental needs, particularly for those who are more medically complex, with an increased risk for systemic and internal family barriers in finding care, based on their 
medical diagnoses. Additionally, those children, along with the majority of SHCN children, cannot understand, assume responsibility for, or cooperate with preventive oral health practices [3]. Several studies reported poorer oral health status among SHCN children than healthy ones [4-7]. Few studies have linked dental caries with obesity in these children [8]. According to Lee et al. [4], the existence and type of SHCN have a decisive effect on oral health conditions.

Oral health-related quality of life (OHRQoL) is defined as a multidimensional construct that reflects comfort when eating, sleeping, engaging in social interactions, and self-esteem: that is, satisfaction with oral health [9]. Several studies assessed the impact of dental caries on OHRQoL of healthy preschool children, primarily using the early childhood oral health impact scale (ECOHIS) as the instrument [10-15]. This scale allows caregivers to answer the questions on behalf of the children, as they lack the necessary cognitive skills to assess them on their own [16]. According to Lee et al. [17], the ECOHIS was more sensitive than other scales in assessing the impact of dental caries on OHRQoL of preschool children; however, few concerns were raised about the suitability of fathers as proxy assessors of their children's OHRQoL compared to mothers [12,18]. Recently, Nora et al. [19] highlighted the negative impact of dental caries on the OHRQoL of preschool children, which tends to coincide with increasing caries' severity. The impact of dental caries' severity on the OHRQoL of SHCN children was not sufficiently investigated $[6,20,21]$, perhaps with limited understanding of what was being evaluated [20].

In Saudi Arabia, a high prevalence of dental caries (77-79\%) was reported among intellectually disabled and medically-compromised children [5,7,18,22]. Pani et al. [23] found that autistic children had reduced OHRQoL, although the impact of dental caries' severity on their OHRQoL was not assessed. To date, the impact of different sociodemographic characteristics or the BMI on the OHRQoL of SHCN children is unclear. The suitability of caregivers as proxy assessors in determining the OHRQoL of SHCN children must be investigated. This is particularly significant in SHCN children when many are incapable of providing an assessment of their OHRQoL, have communication problems, or depend on their caregivers for oral and general health [23].

Thus, the aim of this study was: (1) to assess the impact of dental caries' severity, BMI, and sociodemographic factors on OHRQoL in a subpopulation of children with SHCN; and (2) to assess the suitability of caregivers as proxies to determine the OHRQoL of SHCN children.

\section{Methods}

\subsection{Study Population}

This was a cross-sectional study conducted on a convenience sample of 107 SHCN children and their caregivers who attended the dental clinics of Buraydah maternity and children hospital, Qassim, Saudi Arabia, during the period between February and April 2021. Ethical approval was obtained from the College of Dentistry/Qassim University before the study was conducted (reference \#: EA/6061/2021).

The inclusion criteria for the study were:

(1) Children 4 to 12 years of age;

(2) Cooperative children who allow dental examination;

(3) Children with a diagnosis, confirmed from the children's medical records, of behavioral (e.g., anxiety, attention deficit hyperactivity disorder, autism spectrum disorder), congenital (e.g., Trisomy 21, congenital heart disease), developmental (e.g., cerebral palsy), or cognitive (e.g., intellectual disability) disorders or systemic diseases (e.g., childhood cancer, sickle cell disease) [2];

(4) Caregivers who speak and understand the Arabic language and live in Saudi Arabia;

(5) Caregivers who were willing to participate in the study and sign a written informed consent.

The exclusion criteria were:

(1) Individuals older than 12 years of age; 
(2) Healthy children;

(3) Caregivers and their children who do not speak the Arabic language or reside in Saudi Arabia;

(4) Caregivers who refuse to participate in the study and sign a written informed consent.

Caregivers in the current study were either the mothers or the fathers of the children. Both were the legal guardians of the children.

\subsection{Study Measures}

Caregivers of the children were requested to answer a questionnaire consisting of two parts through a face-to-face interview. The first part comprised sociodemographic questions, while the second part comprised the Arabic version of the ECOHIS. This scale contains 13 questions corresponding to 4 descriptive domains for items included in the child impact section: symptoms, function, psychological, and self-image and social interaction, and 2 domains in the family impact section: parental distress and family function [22]. Response categories are scored from $0=$ never, $1=$ hardly ever; $2=$ occasionally; $3=$ often; $4=$ very often; to $5=$ do not know. The total score ranges between 0 and $52[16,24]$. The sociodemographic questions included the caregiver's gender, caregivers' education level, and occupation as well as the monthly family income, the child's gender and age group, and an overall rating of the child's dental health. Before interviewing the caregivers, the questionnaire was piloted on a sample of 10 caregivers, and all questions were clear.

\subsection{Dental Examination}

Following the completion of the caregivers' questionnaires, dental examination of the children was carried out by one examiner using the daylight, disposable mirror, and explorer. Intra-examiner reliability was verified on a sample of 10 children with a kappa score exceeding 0.9. Dental caries was measured using the decayed (d), missing (m), and filled (f) teeth (dmft) index for the deciduous teeth and the Decayed (D), Missing (M), and Filled (F) teeth (DMFT) index for permanent according to the WHO criteria [25]. Both $\mathrm{dmft}$ /DMFT scores were recorded, separately when applicable, and combined, when applicable, by the sum of $d+m+f+D+M+F$ according to the child's age $(\leq 6$ or $>6$ years) in a similar manner to that adopted by Akhter et al. [6]. A score above null indicates the presence of dental caries, whereas a null score indicates the absence of dental caries [25]. Dental caries severity was then classified according to the number of untreated dental caries ( 0 free of caries; $1-2$ moderate; and $\geq 3$ high), where the upper cutoff values corresponded to the Significant Caries Index [26]. The height and weight of each child were also measured, and the BMI $\left(\mathrm{kg} / \mathrm{m}^{2}\right)$ was calculated based on the updated BMI-for age and gender percentile charts of the AAPD [27], and classified into one of four categories: underweight, healthy, overweight, or obese [28].

\subsection{Data Analysis}

Data were statistically analyzed using the SPSS computer software (Statistical Package for the Social Sciences Version 22, Chicago, IL, USA). Frequencies and percentages of the responses toward each question were generated. They were also calculated for the child's dental health, dental caries status, dental caries severity, BMI, and health condition categories. Because the data were normally distributed, a $t$-test was used to compare means according to the child's dental health and dental caries status, while one-way ANOVA and Tukey post hoc tests were used to compare means and determine the impact of dental caries severity and BMI on the A-ECOHIS score as well as child and family impact sections scores. Poisson regression modeling was used to confirm the association of the different independent variables with the A-ECOHIS score as well as the child and family impact sections scores. Further, the relationship between the dmft/DMFT score of the children and the A-ECOHIS score, as well as the score reported by each caregiver (farther vs. mother), was determined using Spearman's correlation coefficient. Probability values of $p<0.05$ were considered statistically significant. 


\section{Results}

The sociodemographic characteristics, characteristics of the child, and clinical examination findings are summarized in Table 1 . The great majority of children (41.1\%) had malignancy (either acute or in remission). Dental caries was present in $93.5 \%$ of the children, and $81.3 \%$ of those had severe caries. The dmft/DMFT score of the children was $7.11 \pm 5.10$. The greatest score was for children with congenital heart disease (9.52 \pm 6.15$)$, followed by children with down syndrome $(7.00 \pm 5.00)$, while the lowest score was for children with bleeding disorders $(5.77 \pm 3.91)$. With regards to BMI, underweight children had the greatest dmft/DMFT scores $(8.90 \pm 6.19)$, while obese children had the lowest scores $(2.92 \pm 2.43)$. SHCN children whose caregivers rated their dental health as poor had greater $\mathrm{dmft} / \mathrm{DMFT}$ scores $(9.45 \pm 3.02)$ than those whose caregivers rated their dental health as good $(6.84 \pm 5.22)$.

Table 2 shows the responses to the A-ECOHIS items. In the child impact section, 'pain in the teeth, mouth or jaws' was the most frequently reported symptom (48.7\%), while 'feeling upset' (36.4\%) was the most frequently reported in the family impact section. Table 3 provides the descriptive statistics of the A-ECOHIS responses, ranges, floor effect, and comparisons according to dental caries severity. No impacts were reported by $8.4 \%$ of the caregivers in the child impact section and $15.9 \%$ in the family impact section. For overall A-ECOHIS, only $4.7 \%$ reported no impact. The score achieved in the child impact section (7.09) was higher than the family impact section (3.84). In the child impact section, the child function domain had the highest mean score (3.03). In the family impact section, the parental distress domain had a higher mean than the family function domain (2.24 vs. 1.59, respectively). Overall, the A-ECOHIS score from fathers' reports was $11.13 \pm 6.10$ compared to $10.78 \pm 7.01$ from mothers' reports.

Regarding the effect of dental caries severity, children with severe caries, in particular, had the highest mean scores in all domains of the scale, as well as each section separately. A statistically significant difference in mean scores between children with different caries severity was evident in the child symptoms domain, the child function domain, as well as the child impact section. Additionally, a statistically significant difference in mean scores was observed in the parental distress domain, the family impact section, as well as A-ECOHIS score $(p<0.05)$.

Figures 1-3 show the A-ECOHIS score, as well as individual child and family impact section scores, according to the child's dental health, dental caries status, and BMI of the children. The child's dental health had a significant impact on the child impact section score and the overall scale score, while BMI did not have a significant impact.

In the final multivariate model, dental caries severity, child dental health, child age group, and caregiver's education level and occupation were found to impact the OHRQoL significantly (Table 4). Children whose caregiver had no schooling or a primary education level had 1.524 times fewer odds to score higher on the whole scale compared to those whose caregiver had a university degree (95\% confidence interval (CI): 0.523-0.822). Additionally, those whose caregiver's occupation was in the health sector had 1.386 times fewer odds to score higher than those who had a non-working caregiver (95\% CI: 0.539-0.964). On the other hand, children who were $\leq 6$ years old had 1.188 times higher odds to score higher than older children (95\% CI: 1.028-1.373). Moreover, those who had a good dental health rating by their caregiver had 1.45 times fewer odds to score higher than those with a poor rating (95\% CI: 0.574-0.828). Finally, caries-free children had 1.538 times fewer odds to score higher than those with severe caries (95\% CI: 0.482-0.876), and those with moderate caries had 1.814 times fewer odds to score higher than those with severe caries $(95 \% \mathrm{CI}$ : $0.482-0.876)$. 
Table 1. Sociodemographic characteristics, characteristics of the child, and clinical examination findings.

\begin{tabular}{|c|c|c|c|}
\hline Variable & Category & $N$ & $\%$ \\
\hline \multicolumn{4}{|c|}{ Sociodemographic factors } \\
\hline \multirow{2}{*}{ Caregiver gender } & Male & 47 & 43.9 \\
\hline & Female & 60 & 56.1 \\
\hline \multirow{3}{*}{ Caregiver education level } & Never been to school or primary & 16 & 15.0 \\
\hline & Intermediate or secondary & 36 & 33.6 \\
\hline & University & 55 & 51.4 \\
\hline \multirow{3}{*}{ Spouse education level } & Never been to school or primary & 14 & 13.1 \\
\hline & Intermediate or secondary & 41 & 38.3 \\
\hline & University & 52 & 48.6 \\
\hline \multirow{3}{*}{ Caregiver occupation } & Education sector & 32 & 29.9 \\
\hline & Health sector & 9 & 8.4 \\
\hline & $\begin{array}{l}\text { Other than the health and education } \\
\text { sector }\end{array}$ & 18 & 16.8 \\
\hline \multirow{4}{*}{ Spouse occupation } & Unemployed & 48 & 44.9 \\
\hline & Education sector & 22 & 20.6 \\
\hline & Health sector & 9 & 8.4 \\
\hline & $\begin{array}{l}\text { Other than the health and education } \\
\text { sector }\end{array}$ & 40 & 37.4 \\
\hline \multirow{3}{*}{ Family income } & Unemployed & 36 & 33.6 \\
\hline & $\leq 3200$ USD & 54 & 50.5 \\
\hline & $>3200$ USD & 53 & 49.5 \\
\hline \multirow{3}{*}{ Child gender } & Characteristics of the child & & \\
\hline & Boy & 62 & 57.9 \\
\hline & Girl & 45 & 42.1 \\
\hline \multirow{2}{*}{ Child age group } & $\leq 6$ years & 25 & 23.4 \\
\hline & $>6$ years & 82 & 76.6 \\
\hline \multirow{4}{*}{ Health condition } & Bleeding disorders or coagulopathies & 31 & 29 \\
\hline & Congenital heart disease & 27 & 25.2 \\
\hline & Malignancy (acute or in remission) & 44 & 41.1 \\
\hline & Down syndrome & 5 & 4.7 \\
\hline \multirow{2}{*}{ Child dental health } & Good & 96 & 89.7 \\
\hline & Poor & 11 & 10.3 \\
\hline \multicolumn{4}{|c|}{ Clinical examination findings } \\
\hline \multirow{3}{*}{ Dental caries status } & Present & 100 & 93.5 \\
\hline & Absent & 7 & 6.5 \\
\hline & Caries free & 7 & 6.5 \\
\hline \multirow[t]{2}{*}{ Dental caries severity } & Moderate & 13 & 12.1 \\
\hline & High & 87 & 81.3 \\
\hline \multirow{4}{*}{ BMI } & Underweight & 10 & 9.3 \\
\hline & Healthy & 76 & 71 \\
\hline & Overweight & 9 & 8.4 \\
\hline & Obese & 12 & 11.2 \\
\hline
\end{tabular}


Table 2. Distribution of A-ECOHIS responses $(n=107)$.

\begin{tabular}{|c|c|c|c|c|}
\hline & & $\begin{array}{c}\text { Never/Hardly } \\
\text { Ever } \\
N(\%)\end{array}$ & $\begin{array}{c}\text { Occasionally, Often, } \\
\text { Very Often } \\
N(\%)\end{array}$ & $\begin{array}{c}\text { Do not Know } \\
N(\%)\end{array}$ \\
\hline Symptoms * & Pain & $54(50.5)$ & $52(48.7)$ & $1(0.9)$ \\
\hline \multirow{4}{*}{ Function * } & $\begin{array}{l}\text { Difficulty drinking hot or } \\
\text { cold beverages }\end{array}$ & $75(70.1)$ & $27(25.2)$ & $5(4.7)$ \\
\hline & Difficulty eating & $86(80.4)$ & $20(18.7)$ & $1(0.9)$ \\
\hline & Pronunciation difficulty & $91(85)$ & $16(14.9)$ & $0(0)$ \\
\hline & Missed school or daycare & $88(82.2)$ & $17(15.9)$ & $2(1.9)$ \\
\hline \multirow{2}{*}{ Psychology * } & Trouble sleeping & $92(86)$ & $15(14)$ & $0(0)$ \\
\hline & Irritability or frustration & $75(70.1)$ & $28(26.1)$ & $4(3.7)$ \\
\hline \multirow{2}{*}{$\begin{array}{l}\text { Self-image and social } \\
\text { interaction * }\end{array}$} & Avoid smiling or laughing & $92(86)$ & $15(14)$ & $0(0)$ \\
\hline & Avoid talking & $92(86)$ & $15(14)$ & $0(0)$ \\
\hline \multirow{2}{*}{ Parental distress $* *$} & Been upset & $67(62.6)$ & $39(36.4)$ & $1(0.9)$ \\
\hline & $\begin{array}{l}\text { Felt guilty about child's oral } \\
\text { health }\end{array}$ & $72(67.3)$ & $34(30.9)$ & $2(1.9)$ \\
\hline \multirow{2}{*}{ Family function $* *$} & Taken time off work & $84(78.5)$ & $19(17.8)$ & $4(3.7)$ \\
\hline & Financial impact & $87(81.4)$ & $18(16.9)$ & $2(1.9)$ \\
\hline
\end{tabular}

*: Child impact section, ${ }^{* *}$ Family impact section; A-ECOHIS: Arabic version of the Early Childhood Oral Health Impact Scale.

Table 3. Descriptive distributions of the A-ECOHIS responses as well as caries severity for different domains and the overall scale.

\begin{tabular}{|c|c|c|c|c|c|c|c|c|}
\hline \multirow{2}{*}{ Variables } & \multirow{2}{*}{$\begin{array}{l}\text { Items } \\
(N)\end{array}$} & \multirow{2}{*}{$\begin{array}{l}\text { Possible } \\
\text { Range }\end{array}$} & \multirow{2}{*}{$\begin{array}{c}\text { Floor Effect } \\
N \\
\text { (\% Score Zero) }\end{array}$} & \multirow{2}{*}{$\underset{\text { (SD) }}{\text { Mean }}$} & \multicolumn{3}{|c|}{ Caries Severity } & \multirow{2}{*}{$p$-Value } \\
\hline & & & & & Caries Free $^{1}$ & Moderate $^{2}$ & High $^{3}$ & \\
\hline Child impact section & 9 & $0-36$ & $\begin{array}{c}9 \\
(8.4)\end{array}$ & $\begin{array}{c}7.09 \\
(4.66)\end{array}$ & $\begin{array}{c}4.14 \\
(3.85)\end{array}$ & $\begin{array}{c}4.85 \\
(4.39)\end{array}$ & $\begin{array}{c}7.67 \\
(4.62)\end{array}$ & $\begin{array}{l}0.027^{*} \\
(2 \text { vs. } 3)\end{array}$ \\
\hline Child symptoms domain & 1 & $0-4$ & $\begin{array}{c}20 \\
(18.7)\end{array}$ & $\begin{array}{l}1.42 \\
(0.97)\end{array}$ & $\begin{array}{c}0.86 \\
(0.90)\end{array}$ & $\begin{array}{c}0.85 \\
(.899)\end{array}$ & $\begin{array}{l}1.55 \\
(.949)\end{array}$ & $\begin{array}{l}0.013^{*} \\
(2 \text { vs. } 3)\end{array}$ \\
\hline Child function domain & 4 & $0-16$ & $\begin{array}{c}24 \\
(22.42)\end{array}$ & $\begin{array}{l}3.03 \\
(2.68)\end{array}$ & $\begin{array}{l}1.2857 \\
(1.89)\end{array}$ & $\begin{array}{l}1.6923 \\
(2.097)\end{array}$ & $\begin{array}{c}3.3793 \\
(2.72)\end{array}$ & $0.020 *$ \\
\hline $\begin{array}{c}\text { Child psychology } \\
\text { domain }\end{array}$ & 2 & $0-8$ & $\begin{array}{c}35 \\
(32.71)\end{array}$ & $\begin{array}{l}1.64 \\
(1.56)\end{array}$ & $\begin{array}{c}1.1429 \\
(1.21499)\end{array}$ & $\begin{array}{c}1.6154 \\
(1.66024)\end{array}$ & $\begin{array}{c}1.6897 \\
(1.57974)\end{array}$ & 0.675 \\
\hline $\begin{array}{l}\text { Child self-image and } \\
\text { social interaction domain }\end{array}$ & 2 & $0-8$ & $\begin{array}{l}60 \\
(56)\end{array}$ & $\begin{array}{c}0.99 \\
(1.46)\end{array}$ & $\begin{array}{c}0.8571 \\
(1.06)\end{array}$ & $\begin{array}{l}0.6923 \\
(1.03)\end{array}$ & $\begin{array}{l}1.0460 \\
(1.55)\end{array}$ & 0.703 \\
\hline Family impact section & 4 & $0-16$ & $\begin{array}{c}17 \\
(15.9)\end{array}$ & $\begin{array}{c}3.84 \\
(3.31)\end{array}$ & $\begin{array}{l}3.43 \\
(3.86)\end{array}$ & $\begin{array}{c}1.77 \\
(2.20)\end{array}$ & $\begin{array}{c}4.18 \\
(3.31)\end{array}$ & $\begin{array}{l}0.045^{*} \\
(2 \text { vs. } 3)\end{array}$ \\
\hline Parental distress domain & 2 & $0-8$ & $\begin{array}{c}31 \\
(28.97)\end{array}$ & $\begin{array}{l}2.24 \\
(2.28)\end{array}$ & $\begin{array}{l}1.8571 \\
(2.41)\end{array}$ & $\begin{array}{c}0.7692 \\
(1.23)\end{array}$ & $\begin{array}{l}2.4943 \\
(2.32)\end{array}$ & $\begin{array}{l}0.034^{*} \\
(2 \text { vs. } 3)\end{array}$ \\
\hline Family function domain & 2 & $0-8$ & $\begin{array}{c}38 \\
(35.51)\end{array}$ & $\begin{array}{c}1.59 \\
(1.81)\end{array}$ & $\begin{array}{l}1.5714 \\
(1.90)\end{array}$ & $\begin{array}{l}1.0000 \\
(1.47)\end{array}$ & $\begin{array}{l}1.6897 \\
(1.85)\end{array}$ & 0.444 \\
\hline A-ECOHIS items & 13 & $0-52$ & $\begin{array}{c}5 \\
(4.7)\end{array}$ & $\begin{array}{l}10.93 \\
(6.59)\end{array}$ & $\begin{array}{c}7.57 \\
(5.25)\end{array}$ & $\begin{array}{c}6.62 \\
(5.42)\end{array}$ & $\begin{array}{l}11.85 \\
(6.56)\end{array}$ & $\begin{array}{l}0.010^{*} \\
(2 \text { vs } 3)\end{array}$ \\
\hline
\end{tabular}

A-ECOHIS: Arabic version of the Early Childhood Oral Health Impact Scale, * statistically significant. 1 for Caries free, 2 for moderate caries, and 3 for high caries. 


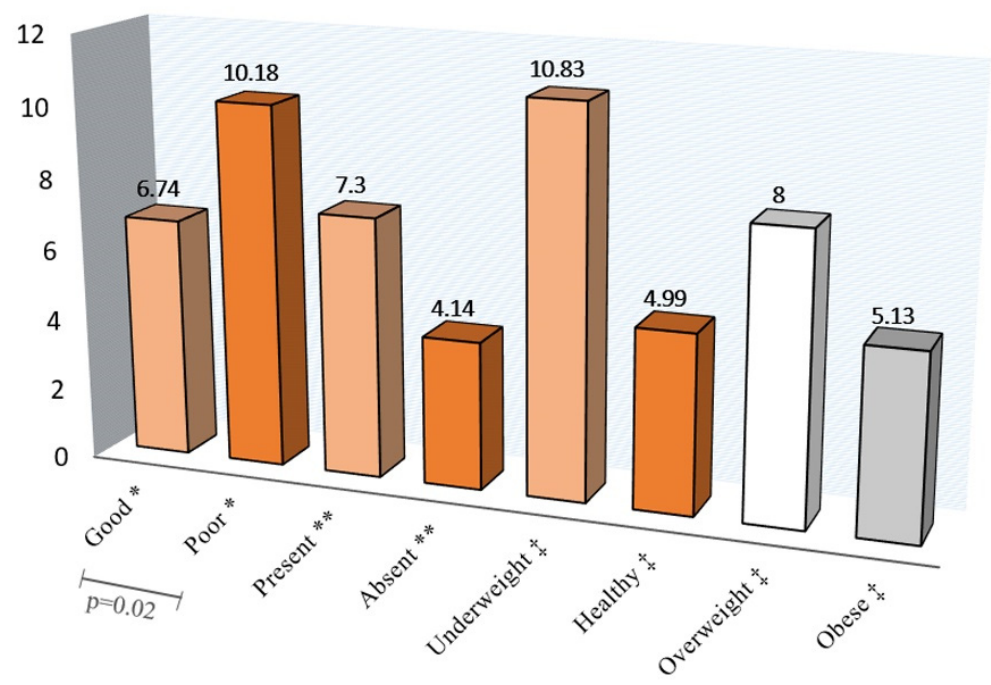

Figure 1. Child impact section score according to the * Child's dental health, ${ }^{* *}$ Dental caries status, and $\ddagger$ Body mass index.

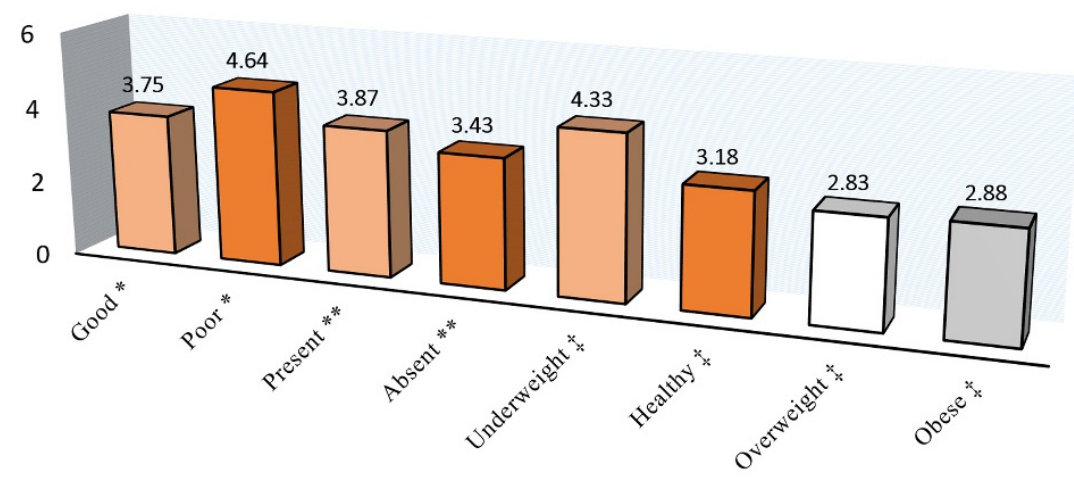

Figure 2. Family impact section score according to the ${ }^{*}$ Child's dental health, ${ }^{* *}$ Dental caries status, and $\ddagger$ Body mass index.

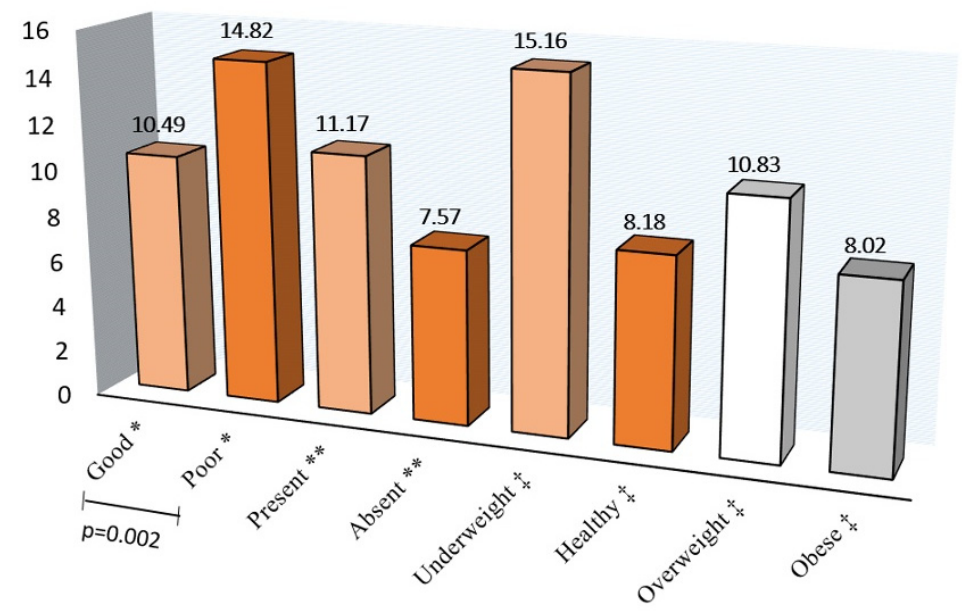

Figure 3. The A-ECOHIS score according to the * Child's dental health, ${ }^{* *}$ Dental caries status, and $\ddagger$ Body mass index. 
Table 4. Variables associated with A-ECOHIS score, child impact, and family impact section scores.

\begin{tabular}{|c|c|c|c|c|}
\hline \multirow{2}{*}{ Variables } & \multirow{2}{*}{ Category } & CIS & FIS & Overall Scale \\
\hline & & \multicolumn{3}{|c|}{ Odds Ratio (95\% Confidence Interval) } \\
\hline Caregiver gender & Male compared to female & $\begin{array}{c}1.280 \\
(1.070-1.532)+\end{array}$ & $\begin{array}{c}0.629 \\
(0.488-0.809) \ddagger\end{array}$ & $\begin{array}{c}1.010 \\
(0.873-1.167)\end{array}$ \\
\hline \multirow{3}{*}{ Caregiver education level } & No schooling or primary & $\begin{array}{c}0.652 \\
(0.493-0.863)+\end{array}$ & $\begin{array}{c}0.665 \\
(0.452-0.979) *\end{array}$ & $\begin{array}{c}0.656 \\
(0.523-0.822) \ddagger\end{array}$ \\
\hline & Intermediate or secondary & $\begin{array}{c}1.073 \\
(0.885-1.301)\end{array}$ & $\begin{array}{c}1.018 \\
(0.780-1.328)\end{array}$ & $\begin{array}{c}1.046 \\
(0.895-1.221)\end{array}$ \\
\hline & University reference & 1 & 1 & 1 \\
\hline \multirow{3}{*}{ Spouse education level } & No schooling or primary & $\begin{array}{c}0.756 \\
(0.562-1.018)\end{array}$ & $\begin{array}{c}1.046 \\
(0.718-1.525)\end{array}$ & $\begin{array}{c}0.856 \\
(0.678-1.081)\end{array}$ \\
\hline & Intermediate or secondary & $\begin{array}{c}0.965 \\
(0.801-1.162)\end{array}$ & $\begin{array}{c}0.806 \\
(0.621-1.045)\end{array}$ & $\begin{array}{c}0.906 \\
(0.779-1.054)\end{array}$ \\
\hline & University reference & 1 & 1 & 1 \\
\hline \multirow{4}{*}{ Caregiver occupation } & Education sector & $\begin{array}{c}0.836 \\
(0.669-1.044)\end{array}$ & $\begin{array}{c}0.987 \\
(0.733-1.328)\end{array}$ & $\begin{array}{c}0.869 \\
(0.728-1.037)\end{array}$ \\
\hline & Health sector & $\begin{array}{c}0.743 \\
(0.520-1.060)\end{array}$ & $\begin{array}{c}0.714 \\
(0.426-1.195)\end{array}$ & $\begin{array}{c}0.721 \\
(0.539-0.964)\end{array}$ \\
\hline & Other & $\begin{array}{c}0.932 \\
(0.733-1.184)\end{array}$ & $\begin{array}{c}0.848 \\
(0.590-1.220)\end{array}$ & $\begin{array}{c}0.894 \\
(0.732-1.091)\end{array}$ \\
\hline & Unemployed reference & 1 & 1 & 1 \\
\hline \multirow{4}{*}{ Spouse occupation } & Education sector & $\begin{array}{c}1.031 \\
(0.813-1.307)\end{array}$ & $\begin{array}{c}0.901 \\
(0.657-1.236)\end{array}$ & $\begin{array}{c}0.994 \\
(0.823-1.200)\end{array}$ \\
\hline & Health sector & $\begin{array}{c}1.050 \\
(0.768-1.436)\end{array}$ & $\begin{array}{c}1.403 \\
(0.955-2.063)\end{array}$ & $\begin{array}{c}1.177 \\
(0.925-1.498)\end{array}$ \\
\hline & Other & $\begin{array}{c}1.243 \\
(1.023-1.510) *\end{array}$ & $\begin{array}{c}0.808 \\
(0.614-1.065)\end{array}$ & $\begin{array}{c}1.079 \\
(0.921-1.264)\end{array}$ \\
\hline & Unemployed reference & 1 & 1 & 1 \\
\hline Family income & $\begin{array}{c}\leq 3200 \text { USD compared to } \\
>3200 \text { USD }^{\text {reference }}\end{array}$ & $\begin{array}{c}0.970 \\
(0.805-1.168)\end{array}$ & $\begin{array}{c}0.968 \\
(0.747-1.253)\end{array}$ & $\begin{array}{c}0.971 \\
(0.836-1.129)\end{array}$ \\
\hline Child Gender & Boy compared to girl reference & $\begin{array}{c}0.986 \\
(0.832-1.168) \\
\end{array}$ & $\begin{array}{c}1.095 \\
(0.870-1.379) \\
\end{array}$ & $\begin{array}{c}1.024 \\
(0.894-1.174) \\
\end{array}$ \\
\hline Child age group & $\leq 6 \underset{\text { reference }}{\text { compared to }>6 \text { years }}$ & $\begin{array}{c}1.059 \\
(0.883-1.271)\end{array}$ & $\begin{array}{c}1.468 \\
(1.153-1.870)+\end{array}$ & $\begin{array}{c}1.188 \\
(1.028-1.373)^{*}\end{array}$ \\
\hline Child dental health & $\begin{array}{l}\text { Good compared to poor } \\
\text { reference }\end{array}$ & $\begin{array}{c}0.581 \\
(0.463-0.729) \ddagger \\
\end{array}$ & $\begin{array}{c}0.915 \\
(0.665-1.258)\end{array}$ & $\begin{array}{c}0.689 \\
(0.574-0.828) \ddagger\end{array}$ \\
\hline \multirow{3}{*}{ Caries severity } & Caries free & $\begin{array}{c}0.592 \\
(0.398-0.881) *\end{array}$ & $\begin{array}{c}0.704 \\
(0.444-1.115)\end{array}$ & $\begin{array}{c}0.650 \\
(0.482-0.876) \dagger\end{array}$ \\
\hline & Moderate & $\begin{array}{c}0.674 \\
(0.509-0.894)+\end{array}$ & $\begin{array}{c}0.366 \\
(0.232-0.578) \ddagger\end{array}$ & $\begin{array}{c}0.551 \\
(0.434-0.700) \ddagger\end{array}$ \\
\hline & High reference & 1 & 1 & 1 \\
\hline \multirow{4}{*}{ Health condition } & Bleeding disorders & $\begin{array}{c}0.626 \\
(0.443-0.885)+\end{array}$ & $\begin{array}{c}1.336 \\
(0.711-2.510)\end{array}$ & $\begin{array}{c}0.776 \\
(0.575-1.048)\end{array}$ \\
\hline & Congenital heart disease & $\begin{array}{c}0.796 \\
(0.571-1.111)\end{array}$ & $\begin{array}{c}1.750 \\
(0.945-3.239)\end{array}$ & $\begin{array}{c}1.010 \\
(0.756-1.351)\end{array}$ \\
\hline & Malignancy & $\begin{array}{c}0.601 \\
(0.428-0.846)+\end{array}$ & $\begin{array}{c}1.282 \\
(0.691-2.379)\end{array}$ & $\begin{array}{c}0.750 \\
(0.558-1.007)\end{array}$ \\
\hline & Down syndrome reference & 1 & 1 & 1 \\
\hline
\end{tabular}

${ }^{*} p<0.05,+p<0.01$, and $\ddagger p<0.001$. CIS: child impact section. FIS: family impact section.

With regards to the association of the caries experience scores of the children and the A-ECOHIS score, there was a significant positive correlation $(p=0.03)$, particularly with the score reported by the mothers $(p=0.032)$ (Figure 4$)$. 


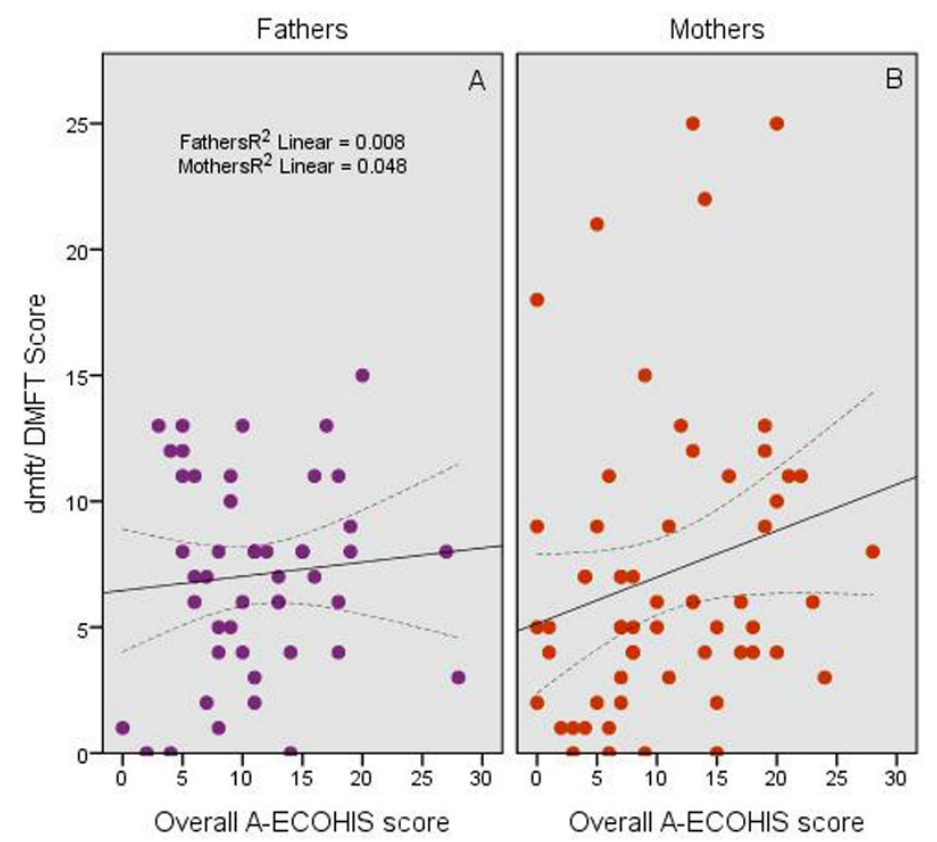

Figure 4. Relationship between the dmft/DMFT scores of the children and the A-ECOHIS score from reports of (A) fathers and (B) mothers. The middle lines show the line of best fit for the correlation and the two lateral lines show the $95 \%$ confidence intervals for the mean values.

\section{Discussion}

This study is the first to assess the impact of dental caries severity, sociodemographic variables, and BMI on the OHRQoL of a subpopulation of SHCN children and to assess the suitability of caregivers (parents) as proxy assessors of the OHRQoL of SHCN children. The A-ECOHIS, which was validated in Saudi Arabia, was chosen as the study instrument due to the lack of instruments directed to evaluate the OHRQoL of SHCN children and age group under study [29], particularly in the Arabic language, and, further, to enable comparisons with previous studies which used the same scale either in English or a different language $[20,21,23]$. Adopting a scale that has been validated in the same country is a strong point as differences in semantics and norms are not expected [30].

In the current study, the $\mathrm{dmft} / \mathrm{DMFT}$ score of the children was 7.11 , with $93.5 \%$ of them having dental caries despite that all children had health insurance coverage. These findings are higher than those reported among SHCN children in Brazil (68.75\%) [20], KSA (56.7\%) [8], and Bangladesh (55.6\%) [6]. However, they are not surprising when the prevalent nature of dental caries in Saudi Arabia is considered among SHCN and healthy children (27.4-79\%) $[5,7,18,22,31,32]$. Additionally, the present study recruited a hospitalbased sample of children who were seeking treatment of pain from self-recognized oral health problems, and consequently, they were expected to have poor oral health $[14,24,33]$. Furthermore, many of the children were taking sugar-sweetened liquid oral medicines regularly or were suffering from hyposalivation (mainly those suffering malignancies) caused by their drugs, the treatment, or the disease process itself [5]. Children with congenital heart disease, followed by those with down syndrome, had the highest dmft/DMFT scores. Storhaug [34] and Brown [5] also found that children with congenital heart disease had high dmft scores or unmet dental treatment needs compared to several disabling conditions. However, the health condition in the present study did not have a significant impact on the OHRQoL of the children, although it had an impact on the child.

In the present study, the OHRQoL was affected in $95.3 \%$ of the children, which is greater than the percentage reported by Faker et al. [20] (68.75\%), and Aggrawal et al. [21] (54\%). The reported A-ECOHIS score in the present study (11.85) was greater than that in the above-mentioned studies (7.10) and (1.38). These findings are not surprising considering the greater caries experience in our population, as having more decayed teeth results in 
greater pain and consequently more impact on the quality of life. Another explanation would be that the children in the current study neither had problems in their verbal ability nor had an intellectual disability; hence, they should be able to express their feelings of pain or discomfort and the reasons for being upset to their caregivers very well [7].

The most frequently reported impact in the present study concerned the oral symptoms domain 'pain in the teeth, mouth, or jaws'. In the family impact section, the 'been upset' item was the most reported one, and overall, negative impacts were greater on the child than on the family. Additionally, heavy floor effects were not observed. These results are consistent with previous studies on SHCN and healthy children from Saudi Arabia and elsewhere $[6,11,20,24]$.

In the present study, the child's dental health, as well as dental caries severity, negatively impacted the OHRQoL, whereas BMI did not have a significant impact. In particular, the child symptoms and function domains and the parental distress domain were affected by caries severity. Children who had either moderate or severe caries were more likely to have worse OHRQoL compared to those without dental caries. These findings seem common among SHCN and healthy children [10-12,19-21,23,24,33,35]. On the other hand, the finding concerning the lack of impact of BMI on OHRQoL perhaps stems from the controversial relation between weight and oral health. According to Alshehri et al. [36], conflicting results of BMI and dental caries in children were reported where some studies reported a positive association, while others reported a negative or no association.

The sociodemographic characteristics, including a family's socioeconomic status, which may be evaluated by income and education, can affect the caregivers' perceptions regarding their child's oral health and is related to oral health conditions [24]. In the present study, the family monthly income did not have an impact on the OHRQoL of the children, unlike previous studies $[35,37]$. The relationship between sociodemographic characteristics and OHRQoL is not clear-cut [21]. In the present study, the caregiver's education level and occupation and the child's age group affected the OHRQoL of the children, where children whose caregiver had no schooling or a primary education level had better OHRQoL compared to those whose caregiver had a university degree. Additionally, those whose caregiver's occupation was in the health sector had better OHRQoL than those with a non-working caregiver. The finding concerning the impact of the caregiver's education level agrees with Chaffee et al. [33], who found that ECOHIS scores were lower when reported by caregivers of less educational attainment. They attributed that to the fact that quality-of-life measures are subjective in nature and may reflect the expectations of individuals who have adapted to a particular life situation, so it is probable that caregivers with a lower educational level are viewing caries as an unavoidable disease, which cannot be controlled, perhaps contributing to cognitive dissonance between caregivers' quality-oflife perceptions and actual experiences. On the other hand, our finding of the impact of the caregiver's occupation sector may be explained by the likelihood that caregivers working in the health sector judge differently due to the nature of their work and the emotional stress level than non-working caregivers who are at home all day focusing on the children. In previous studies on SHCN children using the ECOHIS or a different scale $[6,20,23,28,29]$, the parents were the proxies to determine the OHRQoL of their children, regardless of their age, as many of the children, particularly those with intellectual disability, may not be enrolled in schools, or have communication problems, and consequently, their ability to read, comprehend, and answer the questions reliably, regardless of their age, is expected to be low [30]. In our study, the $\mathrm{dmft} / \mathrm{DMFT}$ scores of the children correlated positively with the A-ECOHIS score. This finding perhaps suggests that the parents, or one of them, maybe opted as a proxy assessor of the OHRQoL of the SHCN child. As such, the reporting parent's gender did not have a significant impact on the OHRQoL of the child; however, the finding that higher A-ECOHIS scores from mothers' reports were translated into higher $\mathrm{dmft}$ /DMFT scores in their children, while those obtained from fathers did not support previous observations $[12,18]$ that fathers may be inept proxy assessors for the OHRQoL but this time of their SHCN child, compared to mothers who are commonly perceived 
as the primary caregivers of the children [18]. However, what seemed concerning in the present study is the inaccurate perception of parents of their SHCN children's dental health as the great majority of the parents (90\%) rated their children's dental health as good when caries experience scores of the children were not low. While, it seemed logical that children of caregivers who rated their children's dental health as poor had higher $\mathrm{dmft} / \mathrm{DMFT}$ scores as well were more likely to have a negative impact on their OHRQoL than those of caregivers who rated their children's dental health as good, the finding that those represented a small proportion (10\%) needs to be emphasized. This highlights a need for a reliable scale that can be used in the future to assess the degree of dependence of SHCN children, at least those without intellectual problems, to avoid the need for proxy assessors to determine their own OHRQoL. In the meantime, mothers could be selected as the proxy assessor of their SHCN children.

The present study has limitations; first, the design of the study is cross-sectional; hence, causal relationships cannot be established. Second, we have used a convenience sample of children and their caregivers from a single hospital; consequently, we do not claim our study to be representative of all SHCN children in the country. Additionally, it is impossible to reflect a wide range of SHCN categories using convenience and relatively small samples; therefore, larger samples stratified by broad SHCN categories will be needed for a more precise analysis. Furthermore, since the children presented seeking dental care, it could be suggested that they have worse OHRQoL than those who do not seek dental care, which may contribute to an overestimation in our results [35]. On the other hand, different studies have assessed the OHRQoL of SHCN and healthy children with convenience samples in hospitals or university institutions [20,28,29,38,39]. Therefore, even though our study is limited to extrapolate the results to the general population, it is relevant to infer associations to SHCN children attending dental services. Future studies should focus on finding a scale to assess the degree of dependence of SHCN children, as it would be best if those children, particularly the ones without intellectual disability, determine their own OHRQoL without the need for proxy assessors.

\section{Conclusions}

Dental caries' severity, caregivers' education level and occupation, and the child's age group had a significant impact on the OHRQoL of the assessed subpopulation of SHCN children; however, BMI did not. Moreover, mothers were better proxies for their SHCN children's OHRQoL.

Author Contributions: Conceptualization, S.N.A.-H.A.; Data curation, R.R.A. and L.S.A.; Formal analysis, S.N.A.-H.A.; Investigation, R.R.A. and L.S.A.; Methodology, R.R.A., L.S.A. and S.N.A.-H.A.; Project administration, R.R.A. and L.S.A.; Resources, S.N.A.-H.A. and R.I.F.; Software, S.N.A.-H.A. and R.I.F.; Supervision, S.N.A.-H.A.; Validation, S.N.A.-H.A. and R.I.F.; Writing-original draft, R.R.A., L.S.A. and S.N.A.-H.A.; Writing-review and editing, S.N.A.-H.A. All authors have read and agreed to the published version of the manuscript.

Funding: This study received no external funding.

Institutional Review Board Statement: Ethical approval was obtained from the ethical committee of the college of Dentistry/Qassim University before the start of the study (reference \#: EA/6061/2021).

Informed Consent Statement: All caregivers in the present study provided their written consent.

Data Availability Statement: The data used to support the findings of this study can be made available upon request to the corresponding author.

Conflicts of Interest: There are no conflicts of interest to declare.

\section{References}

1. American Academy of Pediatric Dentistry. Definition of Special Health Care Needs. Pediatr. Dent. 2018, 40, 16.

2. American Academy of Pediatric Dentistry. Management of Dental Patients with Special Health Care Needs. Pediatr. Dent. 2018, $40,237-242$. 
3. Nelson, L.P.; Getzin, A.; Graham, D.; Zhou, J.; Wagle, E.M.; McQuiston, J.; McLaughlin, S.; Govind, A.; Sadof, M.; Huntington, N.L. Unmet dental needs and barriers to care for children with significant special health care needs. Pediatr. Dent. 2011, 33, 29-36.

4. Lee, J.-Y.; Lim, K.-C.; Kim, S.-Y.; Paik, H.-R.; Kim, Y.-J.; Jin, B.-H. Oral health status of the disabled compared with that of the non-disabled in Korea: A propensity score matching analysis. PLoS ONE 2019, 14, e0208246. [CrossRef]

5. Brown, A. Caries prevalence and treatment needs of healthy and medically compromised children at a tertiary care institution in Saudi Arabia. East. Mediterr. Health J. 2009, 15, 378-386. [CrossRef]

6. Akhter, R.; Hassan, N.M.M.; Martin, E.F.; Muhit, M.; Smithers-Sheedy, H.; Badawi, N.; Khandaker, G. Caries experience and oral health-related quality of life (OHRQoL) of children and adolescents with cerebral palsy in a low-resource setting. BMC Oral Health 2019, 19, 15. [CrossRef]

7. Alzahrani, A.A.H. Parent perspectives on perceived dental pain and dental caries in Saudi schoolchildren with intellectual disability. Spéc. Care Dent. 2019, 39, 310-318. [CrossRef]

8. Ashour, N.A.; Ashour, A.; Basha, S. Association between body mass index and dental caries among special care female children in Makkah City. Ann. Saudi Med. 2018, 38, 28-35. [CrossRef] [PubMed]

9. FDI World Dental Federation. FDI policy statement on oral health and quality of life: Adopted by the FDI General Assembly: 24 September 2015, Bangkok, Thailand. Int. Dent. J. 2016, 66, 11-12. [CrossRef] [PubMed]

10. Rajab, L.D.; Abdullah, R.B. Impact of Dental Caries on the Quality of Life of Preschool Children and Families in Amman, Jordan. Oral Health Prev. Dent. 2020, 18, 571-582. [PubMed]

11. Ramos-Jorge, J.; Pordeus, I.; Ramos-Jorge, M.L.; Marques, L.; Paiva, S. Impact of untreated dental caries on quality of life of preschool children: Different stages and activity. Community Dent. Oral Epidemiol. 2013, 42, 311-322. [CrossRef] [PubMed]

12. Corrêa-Faria, P.; Daher, A.; Freire, M.D.C.; Abreu, M.H.; Bonecker, M.; Costa, L.R. Impact of untreated dental caries severity on the quality of life of preschool children and their families: A cross-sectional study. Qual. Life Res. 2018, 27, 3191-3198. [CrossRef]

13. Guedes, R.S.; Ardenghi, T.M.; Piovesan, C.; Emmanuelli, B.; Mendes, F.M. Influence of initial caries lesions on quality of life in preschool children: A 2-year cohort study. Community Dent. Oral Epidemiol. 2016, 44, 292-300. [CrossRef] [PubMed]

14. Mansoori, S.; Mehta, A.; Ansari, M.I. Factors associated with Oral Health Related Quality of Life of children with severe -Early Childhood Caries. J. Oral Biol. Craniofacial Res. 2019, 9, 222-225. [CrossRef] [PubMed]

15. Naidu, R.; Nunn, J.; Donnelly-Swift, E. Oral health-related quality of life and early childhood caries among preschool children in Trinidad. BMC Oral Health 2016, 16, 128. [CrossRef] [PubMed]

16. Pahel, B.T.; Rozier, R.G.; Slade, G.D. Parental perceptions of children's oral health: The Early Childhood Oral Health Impact Scale (ECOHIS). Health Qual. Life Outcomes 2007, 5, 1-6. [CrossRef]

17. Lee, G.H.; McGrath, C.P.J.; Yiu, C.K.; King, N.M. A comparison of a generic and oral health-specific measure in assessing the impact of early childhood caries on quality of life. Community Dent. Oral Epidemiol. 2010, 38, 333-339. [CrossRef] [PubMed]

18. Pani, S.C.; Badea, L.; Mirza, S.; Elbaage, N. Differences in perceptions of early childhood oral health-related quality of life between fathers and mothers in Saudi Arabia. Int. J. Paediatr. Dent. 2011, 22, 244-249. [CrossRef] [PubMed]

19. Nora, Â.D.; da Silva Rodrigues, C.; de Oliveira Rocha, R.; Soares, F.Z.M.; Minatel Braga, M.; Lenzi, T.L. Is Caries Associated with Negative Impact on Oral Health-Related Quality of Life of Pre-school Children? A Systematic Review and Meta-Analysis. Pediatr. Dent. 2018, 40, 403-411.

20. Faker, K.; Tostes, M.; De Paula, V.A.C. Impact of untreated dental caries on oral health-related quality of life of children with special health care needs. Braz. Oral Res. 2018, 32, e117. [CrossRef]

21. Aggarwal, V.P.; Mathur, A.; Dileep, C.; Batra, M.; Makkar, D.K. Impact of sociodemographic attributes and dental caries on quality of life of intellectual disabled children using ECOHIS. Int. J. Health Sci. 2016, 10, 480-490. [CrossRef]

22. Al-Ogayyel, S.; Ali, S.A.-H. Comparison of dental treatment performed under general anesthesia between healthy children and children with special health care needs in a hospital setting, Saudi Arabia. J. Clin. Exp. Dent. 2018, 10, e963-e969. [CrossRef] [PubMed]

23. Pani, S.C.; Mubaraki, S.A.; Ahmed, Y.T.; Alturki, R.Y.; Almahfouz, S.F. Parental perceptions of the oral health-related quality of life of autistic children in Saudi Arabia. Spéc. Care Dent. 2013, 33, 8-12. [CrossRef] [PubMed]

24. Farsi, N.J.; El-Housseiny, A.A.; Farsi, D.J.; Farsi, N.M. Validation of the Arabic Version of the Early Childhood Oral Health Impact Scale (ECOHIS). BMC Oral Health 2017, 17, 60.

25. World Health Organization. Oral Health Surveys: Basic Methods, 5th ed.; World Health Organization: Geneva, Switzerland, 2013.

26. Bratthal, D. Introducing the Significant Caries lndex together with a proposal for a new global oral health goal for 12-year-olds. Int. Dent. J. 2000, 50, 378-384. [CrossRef]

27. American Academy of Pediatric Dentistry. Body Mass Index (BMI) Charts. Pediatr Dent. 2017, 39, 461-462.

28. Al-Nowaiser, A.M.; Al Suwyed, A.S.; Al Zoman, K.H.; Robert, A.A.; Al Brahim, T.; Ciancio, S.G.; Al Mubarak, S.A.; El Meligy, O.A. Influence of full mouth rehabilitation on oral health-related quality of life among disabled children. Clin. Exp. Dent. Res. 2017, 3, 171-178. [CrossRef]

29. Alves, N.S.; Gavina, V.P.; Cortellazzi, K.L.; Antunes, L.; Silveira, F.M.; Assaf, A.V. Analysis of clinical, demographic, socioeconomic, and psychosocial determinants of quality of life of persons with intellectual disability: A cross-sectional Study. Spéc. Care Dent. 2016, 36, 307-314. [CrossRef]

30. Brown, A.; Al-Khayal, Z. Validity and reliability of the Arabic translation of the child oral-health-related quality of life questionnaire (CPQ11-14) in Saudi Arabia. Int. J. Paediatr. Dent. 2006, 16, 405-411. [CrossRef] 
31. Al-Haj Ali, S.N.; Alsineedi, F.; Alsamari, N.; Alduhayan, G.; BaniHani, A.; Farah, R.I. Risk Factors of Early Childhood Caries Among Preschool Children in Eastern Saudi Arabia. Sci. Prog. 2021, 104, 368504211008308.

32. Al-Malik, M.I.; Holt, R.D.; Bedi, R. Prevalence and patterns of caries, rampant caries, and oral health in two- to five-year-old children in Saudi Arabia. J. Dent. Child. 2004, 70, 235-242.

33. Chaffee, B.W.; Rodrigues, P.H.; Kramer, P.F.; Vitolo, M.R.; Feldens, C.A. Oral health-related quality-of-life scores differ by socioeconomic status and caries experience. Community Dent. Oral Epidemiology 2017, 45, 216-224. [CrossRef] [PubMed]

34. Storhaug, K. Caries experience in disabled pre-school children. Acta Odontol. Scand. 1985, 43, 241-248. [CrossRef] [PubMed]

35. Abanto, J.; Tsakos, G.; Paiva, S.M.; Carvalho, T.S.; Raggio, D.P.; Bönecker, M. Impact of dental caries and trauma on quality of life among 5- to 6-year-old children: Perceptions of parents and children. Community Dent. Oral Epidemiol. 2014, 42, 385-394. [CrossRef]

36. Alshehri, Y.F.A.; Park, J.S.; Kruger, E.; Tennant, M. Association between body mass index and dental caries in the Kingdom of Saudi Arabia: Systematic review. Saudi Dent. J. 2020, 32, 171-180. [CrossRef]

37. Wong, H.M.; McGrath, C.; King, N.; Lo, E. Oral Health-Related Quality of Life in Hong Kong Preschool Children. Caries Res. 2011, 45, 370-376. [CrossRef]

38. Mikael, N.A.; Al-Allawi, N.A. Factors affecting quality of life in children and adolescents with thalassemia in Iraqi Kurdistan. Saudi Med. J. 2018, 39, 799-807. [CrossRef]

39. Locker, D.; Jokovic, A.; Prakash, P.; Tompson, B. Oral health-related quality of life of children with oligodontia. Int. J. Paediatr. Dent. 2010, 20, 8-14. [CrossRef] 